temperature with depth was found by Middendorff than would have been found if the measurements had been made in a shaft immediately after its being pierced. Nevertheless, the fact of the frozen soil extending to a great depth, especially in the valley of the Lena, is not to be contested; nor can there be any doubt as to the extension of frozen soil over large parts of Siberia. M. Yatchevsky attempts to determine its limits from general considerations about the average yearly temperature of separate regions, and the thickness of their snow-covering; and he gives a map of the probable southern limits of the frozen soil in Siberia, which do not differ much from the yearly isotherm of $-2^{\circ} \mathrm{C}$. It must, however, be remarked that though the map approximately shows where the ever-frozen soil may be found beneath the thin layer of soil which thaws every summer, it ought not to be concluded that ever-frozen soil will be found everywhere within those limits. For instance, the granite rocks on the surface of the Vitrin plateau being immediately covered with immense marshes, the water from these marshes infiltrates into the rocks, and, while the marshes are covered during the winter with a crust of ice, their depths remain unfrozen. It may thus be considered certain that immense spaces will be found within the theoretical limits marked on the map, where no ever-frozen soil will be discovered. The Russian Geographical Society is sending out a series of questions, in the hope of obtaining accurate information. and it would be well if the same thing were done in Canada.

AcCorning to a letter from Iceland, dated Reykjavik, February 5,1890 , a translation of which is printed in the current number of the Board of Trade Journal, the population of Iceland during the four years from 1885 to 1888 inclusive has diminished by about 2400 , the total number at the close of each of these years having been, in $1885,71,613$; in $1886,71,521$; in 1887 , 69,641 ; and in $1888,69,224$. This diminution was greatest (1880) in 1887, the explanation for which may be sought in the enormous emigration to America which took place in that year. The diminution in the remaining years, though less sensible, must be attributed to the same cause, as in these years the number of births exceeded that of deaths. The chief diminution has been shown by the northern and eastern districts. The prefecture of Hunavatn in particular has fallen off in respect to inhabitants from 4800 in 1885 to 3785 in 1888 . In Reykjavik, the capital, the population has risen from 3460 to 3599 .

\section{ATMOSPHERIC DUST.}

THE infinitely small particles of matter we call dust, though possessed of a form and structure which escape the naked eye, play, as you are doubtless aware, important parts in the phenomena of nature. A certain kind of dust has the power of decomposing organic bodies, and bringing about in them definite changes known as putrefaction, while others exert a baneful influence on health, and act as a source of infectious diseases. Again, from its lightness and extreme mobility, dust is a means of scattering solid matter over the earth. It may float in the atmosphere as mud does in water, and blown by the wind will perhaps travel thousands of miles before again alighting on the earth. Thus Ehrenberg, in 1828 , detected in the air of Berlin the presence of organisms belonging to African regions, and he found in the air of Portugal fragments of Infusorix from the steppes of America. The smoke of the burning of Chicago was, according to Mr. Clarence King (Director of the United States Geological Survey), seen on the Pacific coast.

Dust is concerned in many interesting meteorological phenomena, such as fogs, as it is generally admitted that fogs are due to the deposit of moisture on atmospheric motes. Again, the scattering of light depends on the presence of dust, and you may remember my showing you on a former occasion that beautiful experiment of Tyndall, illustrating the disappearance of a ray of light when made to travel through a glass receiver free from dust, whilst reappearing as soon as dust is admitted into the vessel. There is no atmosphere without dust, although it varies largely in quantity, from the summit of the highest mountain, where the least is found, to the low plains, at the seaside level, where it occurs in the largest quantities.

The origin of dust may be looked upon, without exaggeration,

2 An Address delivered to the Royal Meteorological Society, January 15, ז890, by Dr. William Marcet, F.R.S., President. as universal. Trees shed their bark and leaves, which are powdered in dry weather and carried about by ever-varying currents of air, plants dry up and crumble into dust, the skin of man and animal is constantly shedding a dusty material of a scaly form. The ground in dry weather, high roads under a midsummer's sun, emit clouds of dust consisting of very fine particles of earth. The fine river and desert sand, a species of dust, is silica ground down into a fine powder under the action of water.

If the vegetable and mineral world crumbles into dust, on the other hand it is highly probable that dust was the original state of matter before the earth and heavenly bodies were formed and here we enter the region of theory and probabilities. In a science like meteorology, where a wide door is open to speculation, we should avoid as much as possible stepping out of the track of known facts; still there is a limit to physical observation, and in some cases we can do no more than glance into the possible or probable source of natural phenomena. Are we on this account to give up inquiring for causes? This question I shall beg to leave you to decide, but where we have such an experienced authority as Norman Lockyer, I think the weight attached to possibilities and theories is sufficiently great to warant my drawing your attention for a few moments to the probable origin of the stars and of our earth.

I dare say many of you have read the interesting article in the Nineteenth Century of November last, by Norman Lockyer, and entitled "The History of a Star." The author proposes to clear in our imagination a limited part of space, and then set possible causes to work ; that dark void will sooner or later be filled with some form of matter so fine that it is impossible to give it a chemical name, but the matter will eventually condense into a kind of dust mixed with hydrogen gas, and constitute what are called nebulæ. These nebulæ are found by spectrum analysis to be made up of known substances, which are magnesium, carbon, oxygen, iron, silicon, and sulphur. Fortunately for persons interested in such inquiries, this dust comes down to us in a tangible form. Not only have we dust shed from the sky on the earth, but large masses, magnificent specimens of meteorites which have fallen from the heavens at different times, some of them weighing tons, may be submitted to examination. From the spectroscopic analysis of the dust of meteorites we find that in addition to hydrogen their chief constituents are magnesium, iron, silicon, oxygen, and sulphur.

There are swarms of dust travelling through space, and their motion may be gigantic. We know, for instance, some stars to be moving so quickly that, from Sir Robert Ball's calculations, one among them would travel from London to Pekin in something like two minutes. From photographs taken of the stars and nebulæe, we are entitled to conclude that the swarms of dust meet and interlace each other, becoming raised from friction and collision to a very high temperature, and giving rise to what looks like a star. The light would last so long as the swarms collide, but would go out should the collision fail ; or, again, such a source of supply of heat may be withdrawn by the complete passage of one stream of dustswarms through another. We shall, therefore, have various bodies in the heavens, suddenly or gradually increasing or decreasing in brightness, quite irregularly, unlike those other bodies where we get a periodical variation in consequence of the revolution of one of them round the other. Hence, as Norman Lockyer expresses it clearly, " it cannot be too strongly insisted upon that the chief among the new ideas introduced by the recent work is that a great many stars are not stars like the sun, but simply collections of meteorites, the particles of which may be probably thirty, forty, or fifty miles apart."

The swarms of dust referred to above undergo condensation by attraction or gravitation; they will become hotter and brighter as their volume decreases, and we shall pass from the nebulæ to what we call true stars.

The author of the paper I am quoting from imagines such condensed masses of meteoric dust being pelted or bombarded by meteoric material, producing heat and light, which effect will continue so long as the pelting is kept up. To this circumstance is due the formation of stars like suns. Our earth originally belonged to that class of heavenly bodies, but from a subsequent process of cooling assumed its present character.

While apologizing for this digression into extra-atmospheric dust, I shall propose to divide atmospheric dust into organic, or combustible, and mineral, or incombustible. The dust scattered everywhere in the atmosphere, and which is lighted up in 
a sunbeam, or a ray from the electric lamp, is of an organic nature. It is seen to consist of countless motes, rising, falling, or gyrating, although it is impossible to follow any of them with the eye for longer than a fraction of a second. We conclude that their weight 'exceeds but very slightly that of the air, and moreover, that the atmosphere is the seat of multitudes of minute currents, assuming all kinds of directions. Similar currents, though on a much larger scale, are also met with in the air. One day last June, from the top of Eiffel's Tower in Paris, I amused myself throwing an unfolded newspaper over the rai carried round the summmit of the tower. At first it fell slowly, carried away by a light breeze, but presently it rose, and, describing a curve, began again to fall. As it was vanishing from sight, the paper seemed to me as if arrested now and then in its descent, perhaps undergoing again a slight upheaval. Here was, indeed, a gigantic mote floating in the atmosphere, and subject to the same physical laws, though on a larger scale, as those delicate filaments of dust we see dancing merrily in a sunbeam.

I recollect witnessing at one of the Friday evening lectures of the Royal Institution in the year 1870 the following beantiful experiment of Dr. Tyndall, illustrative of the properties of atmospheric dust :-If we place the flame of a spirit-lamp or a red-hot metal ball in the track of a beam of light, there will be seen masses of dark shadows resembling smoke emitted in all directions from the source of heat. At first sight this appears as if due to the dust-particles being burnt into smoke; but by substituting for the spirit-flame or red-hot metal ball an object heated to a temperature too low to burn the motes, the same appearance of smoke is observed, hence the phenomenon is not owing to the combustion of the dust. The explanation, however, is obvious. The source of heat, by warming the air in its contact, and immediate proximity, made the air lighter and the motes relatively heavier, consequently they fell, and left spaces free from dust. These spaces in the track of the electric ray appeared dark, or looked as if full of a dense smoke, because the light of the ray could no longer be scattered in them from the absence of dust.

The motes were next examined by Tyndall, to determine whether they were organic or mineral. This was done by driving a slow current of air through a platinum tube heated to redness, and examining this air afterwards in a beam of light; it was then found to darken the ray, having lost the power of scattering light; therefore the dust had been destroyed or burnt by passing through the red-hot platinum tube, clearly showing its organic nature.

We breathe into our lungs day and night this very finelydivided dust, and yet it produces no ill effect, no bronchial irritation. Tyndall has again shown by the analytical power of a ray of light what becomes of the motes we inhale.

Allow me to return to the experiment with the red-hot metal ball placed in the beam of the electric light. Should a person breathe on the heated ball, the dark smoke hovering around it will at first disappear, but it will reappear in the last portions of the air expired. What does this mean? It means that the first portions of air expired from the lungs contain the atmospheric motes inhaled, but that the last portions, after reaching the deepest recesses in the organs of respiration, have deposited there the dust they contained.

It is difficult to say how much of the dust present in the air may become a source of disease, and how much is innocuous. Many of the motes belong to the class of micro-organisms, and the experiment to which we have just referred shows how easily these micro-organisms, or sources of infectious diseases, can reach the lungs and do mischief if they should find a condition of the body on which they are able to thrive and be reproduced. Atmospheric motes, although it has been shown that they are really deposited in the respiratory organs, do not accumulate in the lungs and air-passages, but undergo decomposition and disappear in the circulation. Smoke, which is finely-divided coal-dust, is clearly subjected to such a destructive process; otherwise the smoky atmosphere of many of our towns would soon prove fatal, and tobacco smoke would leave a deposit interfering seriously after a very short time with the phenomena of respiration.

Dust, however, in its physical aspect is far from being always innocuous, and, as you are aware, many trades are liable to suffer from it. The cutting of chaff, for horses' food, is one of the most pernicious occupations, as it generates clouds of dust of an essentially penetrating character. Those engaged in needle manufactures and steel-grinders suffer much from the dust of metallic particles. Stone-cutters, and workmen in plaster of Paris, coal-heavers, cotton and hemp spinners are also engaged in trades injurious to health because of the dust these men unavoidably work in. Those engaged in cigar and rope manufactures, or in flour-mills, hat and carpet manufacturers, are also liable to suffer for the same reason. A number of methods have been adopted, more or less successfully, to rid these trades of the danger due to the presence of dust. I shall not detain you on this subject, which would carry me too far, but merely bring to your notice the fact I observed many years ago, that charcoa has the power of retaining dust in a remarkable degree. I had charcoal respirators made of such a form as to cover both the mouth and nose, and containing about $\frac{1}{2}$-inch thick of charcoal in a granular state. I could breathe through such a respirator in the thickest cloud of dust made by chaff-cutting without being conscious of inhaling any of the dust.

The subject of micro-organisms belongs to the science known as micro-biology. As meteorologists we are chiefly concerned with their distribution in the atmosphere. Micro-organisms are dust-like particles capable of cultivation or reproduction in certain media and at certain temperatures. If a particle of matter known to contain micro-organisms, also called bacilli, be placed on a clear surface of gelatine and maintained at a temperature favourable to its development, in a short time the gelatine will be found to contain a colony of those same bacilli. A fact so often stated as to become a medical truism is that there can be no infectious disease without the presence of the microorganism special to that disease. Open cesspools, putrid meat or vegetable matter, accumulations of refuse, have no ill effects on health unless the micro-organisms of a certain disease, as those of typhoid fever or cholera, be present. On such foul decomposing matters these organisms thrive. They are reproduced with great activity, and become virulent in their effects.

Micro-organisms are scattered everywhere in the atmosphere. Dr. Miguel, at the Monts ouris Observatory at Paris, has made an extensive inquiry into their distribution in air and water. In this country Dr. Percy Frankland has, with praiseworthy labour and perseverance, investigated the subject of microorganisms, and ascertained their number in various localities. The result of his inquiry is that in cold weather, especially when the ground is covered with snow, the number of organisms in the air is very much reduced, and presents a very striking contrast with that found in warmer weather. The experiments made on March 9 show that during cold and dry weather, with a strong east wind blowing over London, a large number of micro-organisms may still be present in the air. It is particularly noticeable that even after an exceedingly heavy rain, and within a few hours afterwards, the number of micro-organisms in the air should be as abundant as usual. Taking an average of the experiments made on the roof of the Science Schools of the South Kensington Museum, the mean number of organisms found in ro litres of air amounted to 35 , while an average of 279 fell on one square foot in one minute. Other experiments made near Reigate and in the vicinity of Norwich present a marked contrast with those undertaken in the South Kensington Museum. There was a remarkable freedom from micro-organisms of the air collected on the heath near Norwich during the comparatively warm April weather, when the ground was dry. The air in gardens at Norwich and Reigate was richer in micro-organism than that of the open country. Again, the number of organisms found in the air of Kensington Gardens, Hyde Park, and Primrose Hill was less than in that taken from the roof of South Kensington, but greater than in the country.

Experiments made in inclosed places, where there is little or no aërial motion, show the number of suspended organisms to be very moderate, but as soon as any disturbance in the air occurs, from draughts or people moving about, the number rapidly increases and may become very great. Experiments made in a railway carriage afford a striking example of the enormous number of micro-organisms which become suspended in the air when many persons are brought together.

Micro-organisms being slightly heavier than air, have an in variable tendency to fall, and on that account frequently collect on the surface of water; hence rivers, lakes, and ponds are constantly being thus contaminated. Micro-organisms in very pure water are not readily disposed to multiply, but traces of decomposing organic matter will induce their reproduction. One remarkable case occurs to me illustrating this fact. In 1884 severe epidemic of typhoid fever broke out in the town of 
Geneva, in Switzerland. The water of the lake in the harbour, which is surrounded by houses on three sides, was then examined by a distinguished micro-biologist, M. Fol, who discovered it to be full of micro-organisms; the water supplied to the town for drinking-purposes was taken from the River Rhone immediately as it flowed out of the harbour. The inquiry was pursued further, and it was found that just outside the harbour, on the surface of the water, there were still a number of microorganisms, though less than in the harbour; but a few fee below the surface, say 3 or 4 feet, they had greatly diminished in number, indeed to such an extent that there were very few present. The obvious remedy was at once carried out. A wooden aqueduct was constructed, opening into the lake about I 50 yards outside the harbour, and some 3 or 4 feet under the surface. As stated by Dr. Dunant, a Geneva physician who has given a very interesting account of this epidemic, ${ }^{1}$ eighteen days after the source-of the water-supply had thus been altered, a marked decline took place in the epidemic, and it was clearly being mastered. A similar epidemic due to a like cause occurred about the same time at Zurich.

There is one point connected with the properties of dust of organic origin which I think cannot fail to be of interest on the present occasion. I mean its inflammability, and its liability to explode when mixed with air. By explosion is meant that the propagation of flame by a very finely-divided material, such as coal-dust, mixed in due proportion with air, may proceed with a rapidity approaching the transmission of explosion by a gaseous mixture.

An interesting lecture was delivered on this subject at the Royal Institution, in April 1882, by Sir Frederick Abel, eirtitled "Some of the Dangerous Properties of Dust." The lecturer refers to instances of explosions in flour-mills, due in all probability to a spark from the grinding mill-stones, occurring in consequence of a deficient supply of grain to the stones.

Messrs. Franklin and Macadam, who investigated the subject, found that accidents of this nature were of frequent occurrence. In May I878 a flour-mill explosion, quite unparalleled for its destructive effects, occurred at Minneapolis, Minnesota. Eighteen lives were lost, and six distinct corn-mills were destroyed. Persons who were near the scene of the calamity heard a succession of sharp hissing sounds, doubtless caused by the very rapid spread of flame through the dust-laden air of the passages inside the mill. The nearest mill to that first fired was 25 feet distance, and exploded as soon as the flames burst through the first mill. The explosion of the third mill, 25 feet from the second, followed almost immediately ; and the other three mills, about I $_{50}$ feet distance in another direction, were at once fired. The fire was attributed to a spark from friction of the mill-stones.

Coal-dust in coal-mines is a cause of accident from explosions, which has been closely investigated in this country, in Germany, and other mining districts. Sir Frederick Abel has given this subject especial attention, and brings it prominently forward in his valuable and exhaustive paper on " Accidents in Mines," read to the Institution of Civil Engineers in I888. Some mines are, of course, more dusty than others, and coal-dusts are not al equally inflammable. That which is deposited upon the sides, top timbers, and ledges in a dry, dusty mine-way is much finer and more inflammable than the coarser dust which covers the floors. The lecture I have referred to alludes to the case of a considerable quantity of coal-dust accidentally thrown over some screens at a pit mouth bursting into flame as the dust cloud came into contact with a neighbouring fire, and burning a man very severely. There appears good ground for believing that fire may travel to a considerable extent through the workings of a mine from the ignition of coal-dust, as will be seen in the following account, extracted from Messrs. W. W. and J. B. Atkinson's book on "Explosions in Mines":-_" An appalling accident happened at the Seaham Colliery, in the county of Durham, on September 8,1880 , at 2.20 a.m., causing the death of 24 men. An explosion occurred in the mine, and a loud report was heard at the surface, accompanied with a cloud of dust from the shaft, but no fire was seen. Owing to damage to the shaft it was more than twelve hours before a descent could be effected, and then a scene of destruction was witnessed by the explorers. Doors and air-crossings destroyed; tubs broken to pieces, and hurled one over the other; timber blown out, attended with heavy falls from the roof; and the bodies of men and horses in many cases

I "Epidémie de fièvre typhoide à Genève en 1884 ," par P. L. Dunant, Revue Médicale de la Suisse Romande, 1887 . terribly mutilated. The explosion was found to have extended over roads of an aggregate length of about 7500 yards, the greatest distance between the extreme points reached being about 3800 yards."

When discussing the cause of this terrible accident, Messrs. Atkinson remark that it was apparently impossible to account for the effects of the explosion on the assumption that it was due to fire-damp, as the presence of fire-damp was most unlikely to occur at any part at which the explosion could have happened; and therefore attention must be turned to coal-dust. There was coal-dust on all the roads traversed by the explosion, and there was coal-dust at the supposed point of origin. These facts are of striking significance. After the explosion, all parts of the mine in which its effects could be traced were covered on the bottom and on flat surfaces with a coating of fine dust, which, when examined under the microscope, appeared to have been acted on by great heat. This fine dust covered the surface for a depth of from $\frac{1}{8}$ to $\frac{1}{2}$ an inch and under. Dust of this kind was entirely absent on those roads over which the explosion had not extended. With reference to the original ignition, a shot had been fired apparently simultaneously with the explosion. The road at the place was of stone, and would probably be coated with the finest coal-dust; and, moreover, just above the spot where the fital shot was fired were large baulks of timber, on which dust was plentifully stored. The shock caused by the explosion would throw the dust into the air, and the flame set fire to it. Thus initiated, the flame would extend through all the roads on which there was an uninterrupted supply of coaldust to support it.

The second part of this address relates to inorganic or mineral dust. When on the Peak of Tenerife in 1878 , engaged in a pursuit mostly of a physiological kind, I had occasion to use a very delicate chemical balance. My object was to determine the amount of aqueous vapour given out of the lungs while in the shallow crater at the summit of the Peak, I2,200 feet above the sea. 'The heat was intense, as the sun shed its nearly vertical rays at midday on the fine white volcanic sand spread over the floor of the crater. At various places rocks projected, covered here and there with crystals of sulphur, and so hot that the hand could scarcely bear coming in contact with them. Anticipating some difficulty in the use of the halance from the action of the wind, I had brought up with me a hamper and a blanket. After placing the hamper sideways, with the lid off, I proceeded, though not without some little trouble, to dispose the balance satisfactorily inside the basket; then, having thrown the blanket over the hamper, I stretched out at full length on the burning sand, nestling under the blanket, much as a photographer would cover himself and camera with a dark cloth. On trying to use the balance, it refused to act ; its beam would not oscillate. A careful examination showed the instrument to be apparently in perfect order, when it occurred to me to wipe the knife-edges at the points of suspension of the beam and pans. The balance then. worked quite well, though but for a few minutes only, again most provokingly declining to oscillate; indeed, it was only by constant wiping of the knife-edges that I succeeded with my experiment. The cause of my trouble was clearly the presence of very fine mineral dust in the air, of which my senses were utterly unconscious. Hence it is that extremely fine particles of mineral dust may exist in the atmosphere, while escaping detection by our senses, and such an occurrence is probably more frequent than generaliy thought.

Prof. Piazzi Smyth, while on the Peak of Tenerife, witnessed strata of dust rising to a height of nearly a mile, reaching out to the horizon in every direction, and so dense as to hide frequently the neighbouring hills. The Report of the Krakatão Commission of the Royal Society contains the following interesting account, p. 42I (Mr. Douglas Archibald's contribution to the Report):- "In 188I, Prof. S. P. Langley ascended Mount Whitney, in Southern California, with an expedition from the Alleghany Observatory; at an altitude of 15 , 000 feet his view extended over one of the most barren regions in the world. Immediately at the foot of the mountain is the Inyo Desert, and in the east a range of mountains parallel to the Sierra Nevada, but only about 10,000 feet in height. From the valley the atmosphere had appeared beautifully clear, but, as stated in Prof. Langley's own words, "from this aërial height we looked down upon what seemed a kind of level dust ocean, invisible from below, but whose depth was six or seven thousand feet, as the upper portion only of the opposite mountain range rose clearly out of it. The colour of the light reflected to us from 
this dust ocean was clearly red, and it stretched in every direction as far as the eye could reach, although there was no special wind or local cause for it. It was evidently like the dust seen in mid-ocean from the Peak of Tenerife-something present all the time, and a permanent ingredient of the earthy atmosphere."

Dust Storms.--These storms, as suggested by Dr. Henry Cook, from whose paper to the Quarterly Journal of the Royal Meteorological Society, in 1880, I am now quoting, may be considered under three heads, according to their intensity-atmospheric dust, dust columns, and dust storms. Dr. Cook, allud. ing to occurrences in India, observes that there are some days on which, however hard and violently the wind may blow, little or no dust accompanies it ; while on others, every little puff of air or current of wind forms or carries with it clouds of dust. If the wind which raises the dust is strong, nothing will be visible at the distance of a few yards, the sun at noon being obscured. The dust penetrates everywhere, and cannot be excluded from houses, boxes, and even watches, however carefully guarded. The individual particles of sand appear to be in such an electrical condition that they are ever ready to repel each other, and are consequently disturbed from their position and carried up into the air.

Dust columns are considered by Dr. Cook as due to electrical causes. On calm, quiet days, when hardly a breath of air is stirring, and the sun pours down its heated rays with full force, little eddies arise in the atmosphere near the surface of the ground. These increase in force and diameter, catching up and whirling round bits of sticks, grass, dust, and, lastly, sand, until a column is formed of great height and considerable diameter, which usually, after remaining stationary for some time, sweeps away across country at great speed. Ultimately it loses gradually the velocity of its circular movement and disappears. In the valley of Mingochar, which is only a few miles in width, and surrounded by high hills, Dr. Cnok, on a day when not a breath of air stirred, counted upwards of twenty of these columns. They seldom changed their places, and, when they did so, moved but slowly across the level tract. They never interfered with each other, and appeared to have an entirely independent existence.

Dr. Cook describes as follows a dust storm which took place at Jacobabad :-- "The weather had been hot and oppressive, with little or no breeze, and a tendency for dust to accumulate in the atmosphere. On the evening of the storm heavy clouds gathered and covered the sky. About 9 p.m. the sky had cleared somewhat, and the moon shone. A breeze sprang up from the west, which increased and bore along with it light clouds of sand. At $9.30 \mathrm{p} . \mathrm{m}$. the storm commenced in all its fury. Vast bodies of sand were drifted violently along. The stars and moon were totally obscured. It became pitch dark, and it was impossible to see the hand held close to the face. The wind blew furiously in gusts, and heaped the sand on the windward side of obstacles in its course. Lightning and thunder accompanied it, and were succeeded by heavy rain. The storm lasted about an hour, when the dust gradually subsided. The sky again became clear, and the moon shone brightly. The storm appeared to have entirely relieved the electrical condition of the atmosphere. A pleasant freshness followed, and the oppressive sensation before mentioned was no longer experienced. This, indeed, is the general effect of storms in Upper Scind. The air is cooled, the atmosphere cleared, and the dusty con dition of the atmosphere which usually precedes them for several days completely disappears."

In the case of a memorable sand storm which occurred at Aden on July $16, \mathrm{1} 878$, and recorded by Lieutenant Herbert Russell, there was a remarkable play of light on the objects which remained within sight. The sudden darkness from the storm gave a peculiar and ghastly tint to the white sand and neighbouring plain, while the curling masses of sand drifted before the gale, resembling a dark yellow smoke. The varied lights, quickly changing, were curious and most grand; the sea a clear green, and Slave Island and Shum-Shum, usually of an arid brown colour, became of an ashy white.

In a dust storm I experienced myself at Luxor, on the Nile, the suffocating effect of the sand as it drove into the lungs and air passages was very trying. People rushed to the immediate river side, where some relief was found.

A book on "Whirlwinds and Dust Storms in India," by P. L. H. Baddeley, Surgeon, Bengal Army, 1860, gives some interesting information on the electrical character of duit storms and dust pillars. When at Lahore in 1847 , this gentleman was desirous of experimenting on the electrical state of the atmosphere in a dust storm, and with this object he projected into the air, on the top of his house, an insulated copper wire fixed to a bamboo ; the wire was brought through the roof into his room, and connected with a gold-leaf electrometer, a detached wire com. municating with the earth. A day or two after, during the passage of a small dust storm, he observed the occurrence of vivid sparks from one wire to the other, and, of course, strongly affecting the electrometer. $\mathrm{He}$ subsequently witnessed at least sixty dust storms of various sizes, all presenting the same kind of phenomena.

Volcanic Dust.-This dust consists mainly of powdered vitrified substances, produced by the action of intense heat. It is interesting in many respects. The so-called ashes or scories shot out in a volcanic eruption are mostly pounded pumice, but they also originate from stones and fragments of rocks which, striking against each other, are reduced into powder or dust. Volcanic dust has a whitish-grey colour, and is sometimes nearly quite white. Thus it is that, in summer, the terminal cone of the Peak of Tenerife appears from a distance as if covered with snow; but there is no snow on the mountain at that season of the year; the white cap on the Peak is entirely due to pumice ejected centuries ago. It is probably to this circumstance that the island and Peak owe their name, as in the Guelph language the words Tener $I f a$ mean white mountain.

The friction caused by volcanic stones and rocks as thiey are crushed in their collision develops a mass of electricity which shows itself in brilliant displays of branch lightning darting from the edges of the dense ascending column. During the great eruption of Vesuvius, in 1822 , they were continually visible, and added much to the grandeur of the spectacle. It not unfrequently happens that dust emitted from Vesuvius falls into the streets of Naples; but this is nothing in comparison with the mass of finely-powdered material which covered and buried the towns of Pompeii, Herculaneum, and Stabiæ in the year 79.

On this occasion, according to the younger Pliny, total darkness from the clouds of volcanic ashes continued for three day, during which time ashes fell like a mantle of snow all over the surrounding country. When the darkness cleared away, the calamity was revealed in all its awful extent, the three towns having disappeared under the showers of dust.

The eruption of Krakatão, a mountain situated on an island in the Straits of Sunda, exceeded, in all probability, in its deadly effects, and as a wonderful phenomenon of Nature, the outburst of Vesuvius in the year 69. The Krakatão Committee of the Royal Society have collected and published in their interesting Report particulars of that memorable eruption, all of them thoroughly authenticated and reliable. The following is extracted from a communication to the Report by Prof. Judd:"On August 26, 1883, it was evident that the long-continued moderate eruptions of Krakatão had passed into the paroxysmal stage. That day, about I p.m., the detonations caused by the explosive action attained such a violence as to be heard at Batavia and Buitzsenborg, about Ioo English miles away. At 2 p.m. Captain Thompson, of the Medea, then sailing at a point 76 miles east-north-east of Krakatão, saw a black mass like smoke rising into the clouds to an altitude which has been estimated at no less than seventeen miles (nearly six times the height of Mont Blanc)."

If this surmise be correct, some idea of the violence of the outburst can be formed from the fact that during the eruption of Vesuvius in 1872 the column of steam and dust was propelled to a height of from 4 to 5 miles only.

At 3 p.m. the explosions were loud enough to be heard 150 miles away. At Batavia and Buitzsenborg the noise is described as being like the discharge of artillery close at hand. Windows rattled, pictures shook, but there was nothing in the nature of earthquake shocks - only strong air vibrations.

Captain Wooldriage, of the Sir R. Sale, viewing the volcano at sunset on the $26 \mathrm{th}$, describes the sky as presenting a most terrible appearance, the dense mass of cloud of a murky tinge being rent with fierce flashes of lightning. At 7 p.m., when from the vapour and dust clouds intense darkness prevailed, the whole scene was lighted up by electrical discharges, and at one time the cloud above the mountain presented the appearance of an immense pine-tree, with the stem and branches formed of volcanic lightning. The air was loaded with excessively fine ashes, and there was a strong sulphurous smell. The steamer G. G. Loudon, within 20 or 30 miles of the eruption, passed through a rain of ashes and small bits of stone. 
Captain Watson, of the ship Charles Bal, at a spot about a dozen miles off the island, records the phenomena of chains of fire appearing to ascend between the volcano and the sky, while on the south side there seemed to be a "continual roll of balls of white fire." These appearances were doubtless caused by the discharge of white-hot fragments of lava rolling down the sides of the mountain. From midnight till $4 \mathrm{a} . \mathrm{m}$. explosions continually took place, the sky one second being intense blackness, the next a blaze of fire.

All the eye-witnesses agree as to the splendour of the electrical phenomena. Captain Woolridge, viewing the eruption from a distance of 40 miles, speaks of the great vapour cloud resembling an immense wall, with outbursts of fork lightning, like large luminous serpents, rushing through the air. After sunset, this dark wall assumed the appearance of a blood-red curtain, with the edges of all the shades of yellow-the whole of a murky tinge, and attended with fierce flashes of lightning. It was reported from the Loudon that lightning struck the mast-head conductor five or six times, and that the mud-rain which covered the masts, rigging, and decks was phosphorescent. The rigging presented the appearance of St. Elmo's fire, which the native sailors were busily engaged putting out with their hands, alleging that, if any portion found its way below, a hole would burst in the ship; not that they feared the ship taking fire, but they thought the light was the work of evil spirits, and that if it penetrated the hold of the vessel, the evil spirits would triumph in their design to scuttle the ship.

By these grand explosive outbursts the old crater of Krakatão was completely'eviscerated, and a cavity formed more than 1000 feet in depth; while the solid materials thrown out from the crater were spread over the flanks of the volcano, forming considerable alterations in their forms.

The sea disturbance which accompanied the eruption of Krakatão was carefully investigated by Captain Wharton, Hydrographer to the Admiralty :-- "The rush of the great sea wave over the land, caused by the violent abrasion in the crater, aided by the action on the water of enormous masses of fallen material, caused great destruction of life and poverty in the Straits of Sunda. By the inrush of these waves on land, all vessels near the shore were stranded, the towns and villages near the coast devastated, two of the lighthouses were swept away, and the lives of 36,380 of the inhabitants sacrificed. It was estimated that the wave was about 50 feet in height when it broke on the shore."

On the morning of the 27 th, between Io and II a.m., three vessels at the eastern entrance of the Straits encountered the fall of mingled dust and water, which soon darkened the air, and covered their decks and sails with a thick coating of mud. Some of the pieces of pumice falling on the Sir $R$. Sale were said to have been of the size of a pumpkin. All day on the 27th, the three vessels were beating about in darkness, pumice-dust falling upon them in such quantities as to employ the crew for hours in shovelling it from the decks and in beating it from the sails and rigging. At Batavia, Ioo miles from Krakatão, the sky was clear at 7 a.m., but at I I a.m. there fell a regular dustrain ; at II.20 complete darkness pervaded the city. The rain of dust continued till $\mathbf{I}$, and afterwards less heavily till 3 p.m.

The speed and distance attained by the pumice ejected from the volcano may be conceived from the fact stated in $\mathrm{Mr}$. Douglas Archibald's contribution to the Report, that dust fell on September 8, more than 3700 English miles from the seat of the eruption.

The great mass of the pumice thrown out during the eruption presented a dirty greyish-white tint, being very irregular in size. It was undoubtedly due to the collision of fragments of pumice as they were violently ejected from the crater ; the noise produced was even more striking than the sound of the explosion.

The dust ejected from Krakatão did not all fall back at the same time upon the sea and earth; as the lightest portions formed into a haze, which was propagated mostly westward. Mr. Archibald states in the Report that most observers agree upon considering this haze as the proximate cause of the twilight glows, coloured suns, and large corona, which were seen for a considerable time after the eruption. The haze was densest in the Indian Ocean and along the equatorial belt, and was often thick enough to hide the sun entirely when within a few degrees from the horizon.

And now, ladies and gentlemen, I must bring this address toa conclusion, and thank you for having followed me over a long,
dusty track. I hope I have succeeded in showing that infinitely small objects, no larger than particles of dust, act important parts in the physical phenomena of Nature, just as small and apparently unimportant events occasionally lead to others of the greatest magnitude.

\section{SOCIETIES AND ACADEMIES. LONDON.}

Royal Society, March 6.- "The Cranial Nerves of the Torpedo" (Preliminary Note). By J. C. Ewart, M.D. Communicated by Prof. M. Foster, Sec. R.S.

The cranial nerves of the torpedo agree in their general arrangement with those of the skate. ${ }^{1}$ The ophthalmicus profundus occupies the usual position, but its ganglion lies in close contact with the Gasserian, and not on a level with the ciliary, ganglion. The trigeminus has the usual distribution, for, notwithstanding the statements in the most recent text-books, ${ }^{2}$ the trigeminus sends no branch to the electric organ. The facial complex includes the superficial ophthalmic, the buccal, and the hyomandibular nerves, all of which have the same distribution as the corresponding nerves in the skate; but the hyomandibular includes or is accompanied by a large bundle of nerve fibres which supply the anterior and inner portion of the electric organ. This large nerve cord (the first electric nerve) has hitherto almost invariably ${ }^{3}$ been described as a branch of the trigeminus. When traced backwards, it is found to spring from the anterior portion of the electric lobe.

The glossopharyngeus, a slender nerve in the skate, is represented in the torpedo by a thick cord which escapes by a large foramen in the outer wall of the auditory capsule. This large nerve consists of two portions, one of which is small and com. pletely covered by the large superficial division. The small deep division, which in its course and distribution closely resembles the glossopharyngeal in the skate, presents on leaving the auditory capsule a distinct ganglionic swelling, beyond which it breaks up into the branchial and otber branches. The large superficial division emanates from the electric lobe behind the origin of the first electric nerve, and at once runs outwards to reach and supply the majority of the columns of the anterior half of the electric organ.

The vagus complex consists of the nervus lateralis, the nervus intestinalis, and of five branchial nerves, of which the two anterior are accompanied by the third and fourth electric nerves. The nervus lateralis, lying superficial to all the other nerves, arises on a level with the root of the glossopharyngeus, and then curves backwards dorsal to the posterior electric nerve to reach the canal of the lateral line. Shortly after leaving the cranium it presents a distinct ganglionic swelling, which is crowded with large cells. The four branchial nerves for the four vagus branchiæ, the slender filament which represents a sixth branchial nerve, and the intestinal nerve lie at first in contact with each other under cover of the third and fourth electric nerves. When the branchial and intestinal nerves are carefully examined, they are found to present four, sometimes five, ganglionic enlarge ments, and in addition ganglionic cells can sometimes be detected at the proximal end of the slender sixth branchial nerve. The third and fourth electric nerves lie over and are especially related to the second and third branchial nerves. These large electric nerves spring from the posterior half of the electric lobe, and find their way outwards partly behind and partly under the auditory capsule, to terminate in the posterior half of the electric organ.

It thus appears that all the electric nerves spring from the electric lobe, that the first accompanies the hyomandibular division of the facial complex, the second the glossopharyngeus, and the third and fourth the first two branchial nerves of the vagus complex. It remains to be seen whether the electric nerves have been derived from motor branches of the nerves with which they are respectively associated by an enormous increase in the number of their fibres, as the muscular fibres were gradually transformed into electric plates.

Physical Society, Feb. 2r.-Prof. G. Carey Foster, F.R.S., Past-President, in the chair.-The following communications were read :-On a carbon deposit in a Blake telephone trans-

"Ewart, "On the Cranial Nerves of Elasmobranch Fishes," Roy. Soc. Proc., vol. 45 , I889.

${ }_{2}$ E.g., McKendrick, "Text-book of Physiology," 1888 , and Wiedersheim, " Grundriss der vergleichenden Ana tomie,"' 1888.

${ }^{3}$ Fritsch is the only author I am acquainted with who does not describe the first electric nerve as a branch of the trigeminus, "Untersuchungen ueber den feineren Bau des Fischgehirns," Berlin, 1878 . 